\title{
A avaliação da atuação da colonoscopia no tratamento do volvo colônico
}

\section{The role of colonoscopy in the treatment of colonic volvulus}

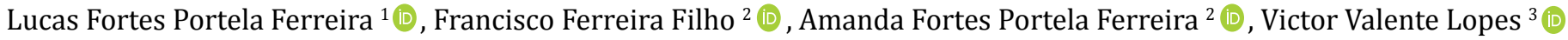 \\ 1. Discente do curso de Medicina pela Universidade Federal do Cariri (UFCA), Barbalha, CE, Brasil. 2. Discente do curso de Medicina pelo Centro Universitário \\ Christus (UNICHISTUS), Fortaleza, CE, Brasil. 3. Discente do curso de Medicina pela Universidade Federal do Ceará (UFC), Fortaleza, CE, Brasil.
}

\begin{abstract}
Resumo
Objetivo: por meio dessa revisão sistemática qualitativa, objetivamos esclarecer qual o papel atual do endoscopista no volvo colônico. Métodos: a pesquisa da literatura foi realizada via PUBMED on-line bancos de dados de janeiro de 2004 a maio de 2017 com os termos "Intestinal Volvulus"[MeSH], "Colonoscopy"[Majr] e adult [MeSH]. Resultados: inicialmente, as estratégias de pesquisa acima mencionadas resultaram em 23 referências. Depois, com base nos critérios de elegibilidade, foram excluídas 12 referências, e 11 foram incluídas. Conclusão: desde a introdução da distorção endoscópica na década de 1940, essa abordagem, juntamente com a ressecção subsequente, tornou-se a principal modalidade terapêutica. A descompressão endoscópica é aceita como o tratamento primário do volvo colônico, no entanto, se houver suspeita de gangrena ou perfuração, pacientes com volvo colônico devem ser submetidos à cirurgia de emergência.
\end{abstract}

Palavras-chave: Volvo intestinal. Colonoscopia. Adulto.

\begin{abstract}
Objective: through this qualitative systematic review, we aimed to elucidate the current role of the endoscopist in the colonic volvo. Methods: the literature search was performed via PUBMED online databases from January 2004 to May 2017 with the terms "Intestinal Volvulus" [MeSH] "Colonoscopy" [Majr] and adult [MeSH]. Results: initially, the above mentioned search strategies resulted in 23 references. Then, based on the eligibility criteria, 12 references were excluded and 11 were included. Conclusions: since the introduction of endoscopic distortion in the 1940s, this approach, along with subsequent resection, has become the primary therapeutic modality. Endoscopic decompression is accepted as the primary treatment of colonic volvo; however, if gangrene or perforation is suspected, patients with colonoscopy should undergo emergency surgery.
\end{abstract}

Key words: Intestinal volvulus. Colonoscopy.Adult.

INTRODUÇÃO

Em todo o mundo, o vólvulo colônico é a terceira principal causa de obstrução do intestino grosso. O termo "volvulus" é originário do latino volvere ou "torcer". No caso do volvulu do colón, o termo refere-se à torção do cólon, na maioria das vezes, no sigmoide, de forma a causar obstrução, possivelmente levando à isquemia e à gangrena ${ }^{1}$. Em um estudo de 546 casos de volvulu do colo, foi encontrado com maior frequência, no sigmoide $(60,9 \%)$, seguido do ceco $(34,5 \%)$, do cólon transverso $(3,6 \%)$ e da flexura esplênica $(1 \%)^{2}$.

O vólvulo sigmoide (VS) é uma condição em que o cólon sigmoide envolve-se em si e em seu mesentério, causando, assim, uma obstrução do intestino grosso ${ }^{3,4,5}$. A maior taxa de incidência de VS é entre a quarta e oitava décadas de vida (faixa etária média entre 52-68 anos) e a relação entre homens e mulheres varia de 1,4: 1 a 4: $1^{3,6}$.

A incidência de vólvulos de cólon sigmoide varia muito em todo o mundo, atingindo até $10 \%$ ou menos de obstrução intestinal no Oeste, mas até $80 \%$ nos Andes, Bolívia ${ }^{7,8}$. O volvo do cólon sigmoide é a forma mais comum de volvulus nos Estados Unidos e Europa Ocidental, embora, em geral, seja uma forma rara de obstrução colônica. Em outras partes do mundo, incluindo Ásia, África e regiões menos desenvolvidas, pode representar 20 a $50 \%$ da obstrução intestinal ${ }^{9}$. Menores percentuais de obstrução relacionada ao VS no mundo ocidental em comparação com outros locais podem ser devidos à dieta com baixo consumo de fibra nos países ocidentais, levando a maiores incidências de diverticulose e câncer colorretal, levando as etiologias a serem maiores causas para obstrução. Além disso, dietas ricas em fibra ingeridas em outras partes do mundo podem levar ao alongamento do cólon. Isso pode ser um fator predisponente para o volvulus. $O$ cólon sigmoide, por ter anexos próximos à sua junção com o cólon e o reto descendentes, tornam-no uma localização privilegiada para torção quando alongado ${ }^{1}$.

A presença de um cólon sigmoide redundante e móvel, com uma base estreita na raiz mesentérica, é um dos principais fatores predisponentes para o volvulo sigmoide. Outros fatores predisponentes, como idade, dieta rica em fibras, constipação 
crônica, história de cirurgia abdominal, episódios prévios de volvulus, dismotilidade, cólon sigmóide redundante com mesentério alongado e base estreita, institucionalização, megacólon, gravidez, diabetes ou doenças neurológicas e psiquiátricas, como demência ou esquizofrenia e uso de drogas psicoativas foram descritos na literatura ${ }^{1,6,710,11}$. Embora o VS seja conhecido como uma causa de hipocalemia ${ }^{12}$ e acredita-se que a hipocalemia seja um fator de risco para o VS intermitente ${ }^{13}$, os achados laboratoriais de rotina não são indicadores claros de VS, e essas descobertas são, muitas vezes, relacionadas a obstruções intestinais e/ou à isquemia intestinal ou gangrena ${ }^{3,14}$.

Uma característica clara do VS é a sua tendência de recorrer. A taxa de recorrência de VS varia de 13 a 85\% ${ }^{15-17}$; Atamanalp $(2013)^{3}$ observou que $25,1 \%$ dos nossos pacientes apresentaram episódios prévios de VS. Do mesmo modo, as comorbidades frequentemente acompanham o diagnóstico de VS, que variou de 25 a $63 \%$ dos pacientes com VS ${ }^{15-17}$, e $25,7 \%$ dos pacientes de Atamanalp $(2013)^{3}$ com VS apresentaram comorbidades graves 18,19 . Finalmente, o VS também é comumente associado a choque séptico e/ou hipovolêmico, visto em $7-13,5 \%$ dos pacientes com VS ${ }^{15-17}$. O choque associado ao VS é devido a comorbidades e atrasos na busca de atendimento médico ${ }^{15,20}$, o último dos quais, na opinião desse autor, está associado a baixos níveis socioeconômicos ${ }^{3}$. Apesar de os fatores de risco serem bem conhecidos, a patogênese exata do volvo sigmoide não está bem estabelecida ${ }^{7,18}$.

Raveenthiran et $\mathrm{al}^{4}$, recentemente, forneceram mais informações sobre a fisiopatologia do vulvulo sigmoide agudo. O aumento da pressão intraluminal prejudica a perfusão capilar após a ocorrência de volvo sigmoide agudo. A obstrução mecânica devido à torção dos vasos mesentéricos e a trombose das veias mesosigmoides contribuem para a isquemia. A lesão isquêmica na mucosa ocorre mais cedo do que em outras camadas colônicas e facilita a translocação bacteriana e a toxemia. Uma válvula ileo-cecal competente converte o cólon proximal em um segundo "circuito fechado". O aumento da pressão intra-abdominal resulta na "síndrome do compartimento abdominal". A correção rápida e otimizada dessas características fisiopatológicas são vitais para melhorar o prognóstico do vulvulo sigmoide agudo ${ }^{6,11}$.

O diagnóstico de vólvulo sigmoide agudo é estabelecido por achados clínicos e radiológicos. Na maioria dos pacientes, exame físico completo e radiografias abdominais são adequados para alcançar o diagnóstico6. O intervalo entre o desenvolvimento dos sintomas e a hospitalização varia de 6h-15h a 7 dias (média de $38,7 \mathrm{~h})^{3,6}$.

O ceco é o segundo local mais comum para o volvo. A incidência do volvo cecal é relatada entre 2,8 e 7,1 por milhão de pessoas por ano. Representa 1 a 1,5\% de todas as obstruções intestinais do adulto e 25 a $40 \%$ de todo o vulvulus envolvendo o cólon. Anatomicamente, esse diagnóstico envolve a íleo terminal, ceco e cólon proximal direito. Existem duas variantes do vólvulo cecal: a rotação axial do cólon proximal direito, ceco e íleo terminal em torno de seu mesentério, geralmente no sentido horário; e a dobra anterosuperior do ceco sem rotação axial ${ }^{1}$.

A etiologia do volvo cecal, provavelmente, está relacionada à embriogênese tardia; o ceco gira no sentido anti-horário do lado esquerdo do abdômen ao quadrante inferior direito. Como consequência, o mesentério do colo direito se fixa a estruturas retroperitoneais. Se o paciente tiver uma fixação incompleta, existe o risco de formação de volvulus cecal. Dada a incidência relativamente menor de vólvulo cecal, outros fatores devem estar em jogo. Os relatórios mostraram que 23 para $53 \%$ dos pacientes com volvo cecal tiveram antecedentes de cirurgia abdominal. Isso pode ser porque as adesões secundárias à cirurgia abdominal formam um ponto de fixação para a cólon direito móvel girar, causando a torção que conduz ao comprometimento intestinal. Constipação crônica, obstrução de cólon distal, dietas ricas em fibras, colonoscopia prévia e gravidez tardia também foram identificados como fatores importantes no desenvolvimento do vólvulos cecal ${ }^{1}$.

O vólvulo do cólon transverso e da flexura esplênica são raramente descritos. A maioria dos pacientes são mais jovens, muitas vezes, na segunda ou terceira décadas de vida, sendo mais prevalente no sexo feminino.

Fatores que predispõem ao volvo cólon transverso incluem o impedimento à defecação, como obstrução distal ou constipação crônica, alongamento e redundância do cólon, e o estreitamento do mesentério, fazendo que as flexões estejam mais próximas ${ }^{1}$.

A apresentação clínica do volvo depende da duração e do grau de torção do cólon ${ }^{4}$. Dor abdominal, distensão abdominal e constipação, que são observados em média de 93,0, 89,9 e $83,0 \%$ dos casos de VS endêmico, enquanto uma média de 64,8 , 88,9 e $52,4 \%$ dos casos de VS esporádicos, respectivamente, são os sinais clínicos mais comuns. Juntos, esses são conhecidos como a tríade clássica do VS ${ }^{4,15,17}$. A tríade clássica de VS foi vista em uma porcentagem elevada dos pacientes da série de Raveenthiran et al. (2010). Outras queixas comuns incluem vômitos $(40,6-47,6 \%)$, náusea $(29,5-36,1 \%)$, diarreia $(9,5-$ $21,6 \%)$ e anorexia. Além disso, distensão abdominal assimétrica e abdome tenso, que são observados na média de $73,9 \%$ dos pacientes com volvo colônico, são os principais achados clínicos. Outros achados incluem reto vazio $(42,8-63,6 \%)$, diminuição dos sons intestinais (31,2-58,9\%), aumento dos sons intestinais (41,1-68,8\%), peristaltismo visível (7,3-31,9\%), desidratação $(28,8-50,5 \%)$, febre $(25,9-28,1 \%)$, sinal de defesa muscular/ Blumberg (8,9-14,9\%), melena (7,3- 11,8\%), hematêmese $(11,5 \%)$, dispneia $(6,8-88 \%)$, massa abdominal e odor de fezes. A presença de melena ou defesa muscular e/ou sinal de Blumberg podem ser indicadores de gangrena intestinal e/ou perfuração com peritonite ${ }^{1,3,4,6,15,17}$.

As radiografias abdominais isoladas podem ser diagnosticadas em 60 a $75 \%$ dos $\operatorname{casos}^{1,15,21}$. No volvo colônico, embora os principais sinais diagnósticos de raios $\mathrm{X}$ abdominais simples 
sejam a presença de um cólon sigmoide dilatado e/ou níveis múltiplos de fluxo de ar intestinais, vários sinais são descritos, incluindo o sinal de ômega ou ferradura (formação do cólon sigmoide dilatado em um tipo de ômega ou de ferradura), sinal de bico-pássaro (aspectos afiados do bico-pássaro das extremidades dos segmentos sigmoides), sinal $U$ invertido ou $\mathrm{V}$ (formações $\mathrm{U}$ ou $\mathrm{V}$ das extremidades dos segmentos sigmoides), sinal $Y$ (uma formação de tipo $Y$ do mesentério e das haustrações sigmoides inchadas), sinal do hemisfério norte (uma formação de cólon sigmoide dilatada que ascende cefalicamente ao cólon transverso), sinal do grão de café (forma de grão de café formada pelo cólon sigmoide dilatado), tubo interno curvado ou sinal de "ás de espada" (um laço dilatado a haustração do cólon sigmoide), sobreposição pélvica esquerda ou sinal de sobreposição do flanco esquerdo (dois segmentos de cólon sigmoides distendidos que se tocam na pelve ou flanco esquerdo), sinal de sobreposição do fígado (intestino distendido tocando o limite inferior da sombra hepática no quadrante superior direito) e sinal da fossa ilíaca esquerda vazia (ausência de sombra de gás na fossa ilíaca esquerda) $)^{3,4,15,22-24}$.

Se forem necessários estudos radiológicos adicionais, pode-se obter tomografia computadorizada (TC) ou enema baritado. A TC abdominal, geralmente, mostra um mesentério sigmoide girado, além de laços sigmoides dilatados e níveis intestinais com fluidos de $\operatorname{ar}^{3-5,18,22}$. Achados semelhantes geralmente são encontrados na análise abdominal de ressonância magnética ${ }^{4,5}$. Tanto a TC quanto a RNM são ferramentas valiosas para o diagnóstico de volvo. Além disso, esses exames podem ajudar a excluir outras causas de obstrução intestinal, como a malignidade intestinal, e diagnosticar complicações como a perfuração ${ }^{3}$. A TC abdominal, geralmente, revela um cólon dilatado com um nível de ar/fluido e o "sinal de turbilhão", que representa o cólon e o mesentério torcidos ${ }^{6}$. O enema baritado, juntamente com filmes simples, pode aumentar a precisão diagnóstica em até $100 \%{ }^{25}$. Como a aparência do cólon dilatado em radiografias também pode ser indicação de neoplasia ou megacólon, esses diagnósticos precisam ser descartados. A descompressão endoscópica subsequente pode identificar neoplasias. A presença de megacólon pode alterar a abordagem cirúrgica, uma vez que sua presença em paciente com vólvulo sigmoide leva à maior possibilidade de recorrência após a colectomia do sigmoide ${ }^{1,26}$.

A principal causa de diagnóstico errado é a presença de achados concomitantes indicativos de obstruções do intestino delgado, que resultam em diagnósticos impróprios de obstruções. Outras formas de obstrução do intestino grosso, especialmente aquelas causadas por malignidade colorretal, pseudo-obstrução, íleo paralítico, megacólon tóxico, doença de Hirschsprung, vólvulo cecal e divertículo gigante do cólon podem imitar ou confundir clínica ou, radiologicamente, o volvo, mais especificamente o $V^{4,5,27}$. As taxas de precisão diagnóstica da análise de TC e RNM se aproximam de $100 \%$ para o VS ${ }^{4,5,18}$, e é claro que o uso dessas técnicas, sempre que possível, melhora a taxa de diagnóstico correto da doença. Da mesma forma, a endoscopia flexível possui alto valor diagnóstico para $\mathrm{VS}^{4,5}$ e foi promovida como a

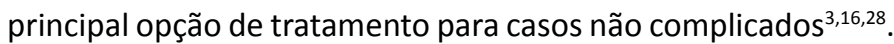

Apesar da tecnologia moderna, o diagnóstico de VS é feito apenas por laparotomia ou autópsia em 10-15\% dos pacientes4,18. Esses achados sugerem que VS pode ser difícil de diagnosticar em alguns casos. Embora o diagnóstico de VS seja frequentemente feito por achados clínicos, radiológicos e ocasionalmente operacionais, TC, RNM ou endoscopia flexível podem ser ferramentas valiosas para facilitar diagnósticos adequados3. Uma vez diagnosticado, o vólvulo sigmoide, geralmente, requer intervenção, pois apenas $2 \%$ se resolvem espontaneamente ${ }^{7,29,30}$.

O tratamento do vólvulo colônico permanece controverso e depende do procedimento eleito e da abordagem terapêutica mais apropriada em termos de estado clínico do paciente, localização do problema, suspeita ou presença de peritonite, viabilidade intestinal e experiência da equipe cirúrgica ${ }^{6,10}$.

O diagnóstico precoce e correto dessa doença é essencial para um tratamento adequado destinado a corrigir alterações fisiopatológicas anormais e a restaurar o trânsito intestinal causado pelo vólvulo6,31,32. A descompressão endoscópica é geralmente aceita como o tratamento primário do vólvo sigmoide $^{31,32}$.

O atraso no tratamento pode ter consequências graves. A obstrução em circuito fechado resulta em aumento da pressão intraluminal com comprometimento inicialmente venoso, e depois do fluxo sanguíneo arterial. Isso pode resultar em complicações com risco de vida, como isquemia intestinal, gangrena e perfuração ${ }^{29}$. Uma vez que a peritonite existe, o manejo cirúrgico é obrigatório ${ }^{7}$. Uma alta mortalidade (30 a $50 \%$ ) ocorre em pacientes com alterações gangrenosas ou em pacientes idosos com doença concomitante do sistema cardiovascular, respiratório ou renal ${ }^{11,33}$. O tratamento não operatório é adotado se não houver evidência dessas condições. Enema bárico, tubos retais, sigmoidoscopia rígida e flexível foram adotados pelos clínicos como métodos terapêuticos ${ }^{34}$. A colonoscopia, além de ser uma medida terapêutica, permite a avaliação da mucosa colônica e, portanto, a presença ou ausência de sinais de isquemia e é efetiva em mais de $70 \%$ dos pacientes ${ }^{6}$.

No entanto, sem um eventual manejo cirúrgico, a recorrência é comum. Após uma descompressão não operatória bemsucedida, há uma propensão reconhecida para a recorrência, que é supostamente tão alta como $90 \%$, com uma mortalidade de até $33 \%$. Essa abordagem sinalizou o início da redução transanal do volvo de sigmoide, que é usado hoje. Com a melhoria da tecnologia, o cirurgião tem a opção não apenas de desvios com um proctoscópio rígido, mas também a introdução do sigmoidoscópio flexível. Muitos autores relataram sucesso em seu uso para descomprimir o volvo não apenas no sigmoide, mas também em outros locais anatômicos e defendem seu uso em pacientes incapazes de tolerar laparotomia35. Devido a altas taxas de recorrência, a descompressão endoscópica é 
considerada uma medida temporária ${ }^{1}$.

O tratamento terapêutico dessa doença permanece controverso, mas o tratamento conservador, geralmente, é considerado apropriado para minimizar o tratamento invasivo e evitar a cirurgia emergente ${ }^{16,36}$. Depois da resolução endoscópica temporária, recomenda-se a ressecção eletiva do cólon sigmoide nos casos em que os riscos associados à cirurgia eletiva são inferiores àqueles associados à recorrência. Atualmente, a principal terapia para volvo colônico é a cirurgia. No entanto, o reparo cirúrgico não é aplicável a pacientes com idade avançada, ausência de sintomas intestinais e múltiplas comorbidades. Assim, estudos anteriores coletaram poucos dados sobre o tratamento endoscópico do volvo colônico ${ }^{36}$.

\section{MÉTODOS}

Foi realizada uma revisão sistemática qualitativa dos artigos sobre o papel do endoscopista no volvo colônico em bases de dados eletrônicos previamente escolhidos.

A pesquisa da literatura foi realizada via PUBMED on-line, bancos de dados de janeiro de 2004 a maio de 2017. A razão para limitar a pesquisa a 2004-2017 foi que, durante esse período, houve uma expansão dos trabalhos relacionada ao tema.

Inicialmente, os termos de busca navegados na base de dados PUBMED foram:

1 "Intestinal Volvulus"[MeSH];

2 "Colonoscopy"[Majr]; e

3. adult $[\mathrm{MeSH}]$.

As seguintes pesquisas foram realizadas: 1 AND 2 AND 3. Além do termo MeSH e termo MeSH primário (Majr), optou-se por utilizar o filtro "Adult: 19+ years "devido à incidência da faixa pediátrica e adulto jovem serem mais baixas e as características clínico -radiológicas poderem ser diferentes. A estratégia de busca e os artigos encontrados foram analisados em duas ocasiões separadas para assegurar uma amostragem adequada.

A análise dos artigos seguiu, previamente, determinados critérios de elegibilidade. Adotamos os seguintes critérios de inclusão: (1) referências escritas em Inglês; (2) os artigos originais com texto completo acessível on-line na base de dados PUBMED; (3) estudos pertencentes à avaliação da atuação do endoscopista no tratamento do volvo colônico; (4) estudos observacionais (analíticos ou descritivos, exceto relatos de casos), estudos experimentais ou quase-experimentais, tanto prospectivos ou retrospectivos. Excluídos foram: (1) estudos que não incluam o tema proposto; (2) artigos originais sem texto completo acessível on-line na base de dados PUBMED; (3) alguns estudos não originais, incluindo editoriais, comentários, prefácios e comunicações breves

Em seguida, cada artigo da amostra foi lido em conjunto, e os elementos de dados, em seguida, foram extraídos e entraram em uma matriz que inclui autores, revista, descrição da amostra do estudo e os principais resultados. Alguns dos estudos tratam não só com as formas como o endoscopista deve agir no volvo sigmoide, mas também como e quando a conduta cirúrgica deve ser tomada.

\section{RESULTADOS}

Inicialmente, as estratégias de pesquisa acima mencionados resultaram em 23 referências. Depois, com base nos critérios de elegibilidade, foram excluídas 12 referências e 11 foram incluídas, conforme mostrado abaixo no gráfico 1 e quadro 1:

Gráfico 1: porcentagem de publicações encontrada, dividida por tipo de documento (esquerda) e após aplicação dos critérios de elegibilidade (direita).

Gráfico 1. porcentagem de publicações encontrada, dividida por tipo de documento (esquerda) e após aplicação dos critérios de elegibilidade (direita).

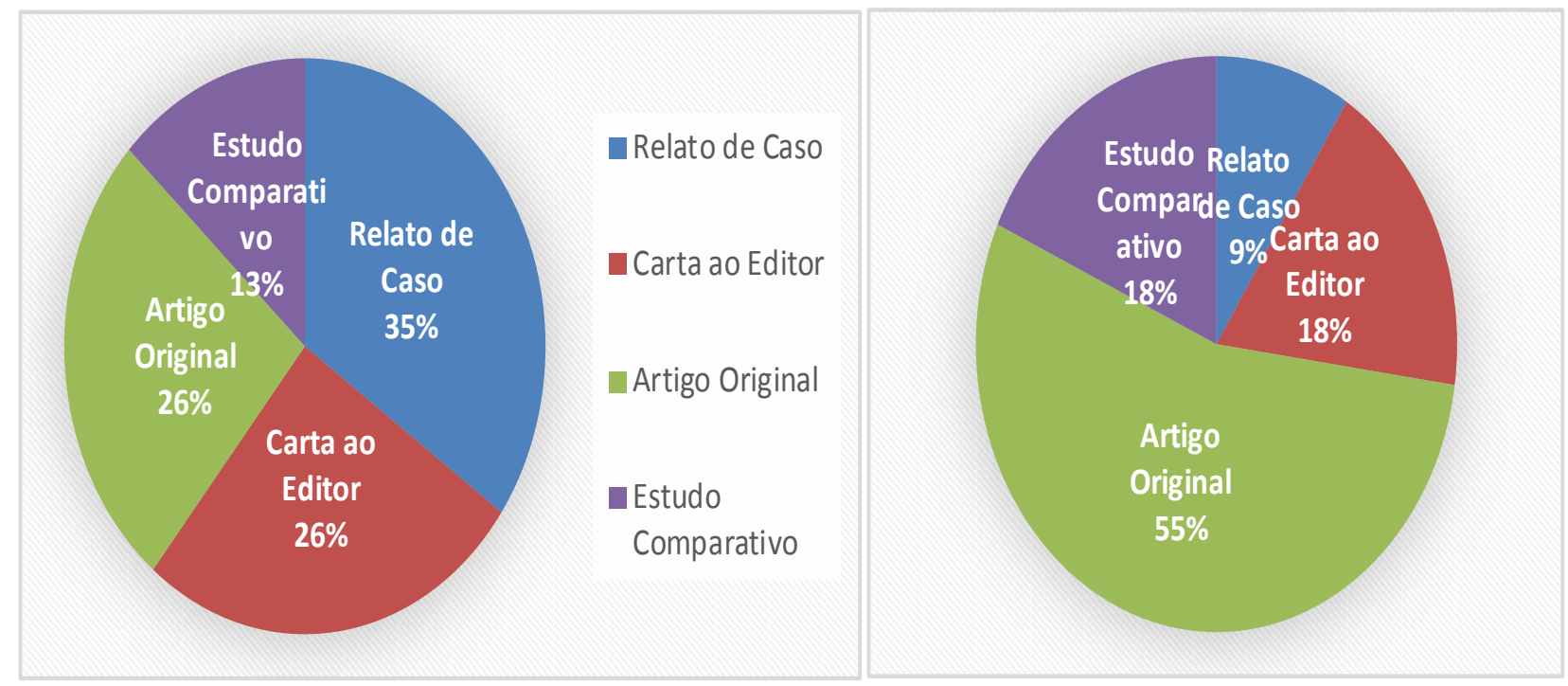


Quadro 1. resultados obtidos por meio dos descritores da metodologia e motivo caso não incluso.

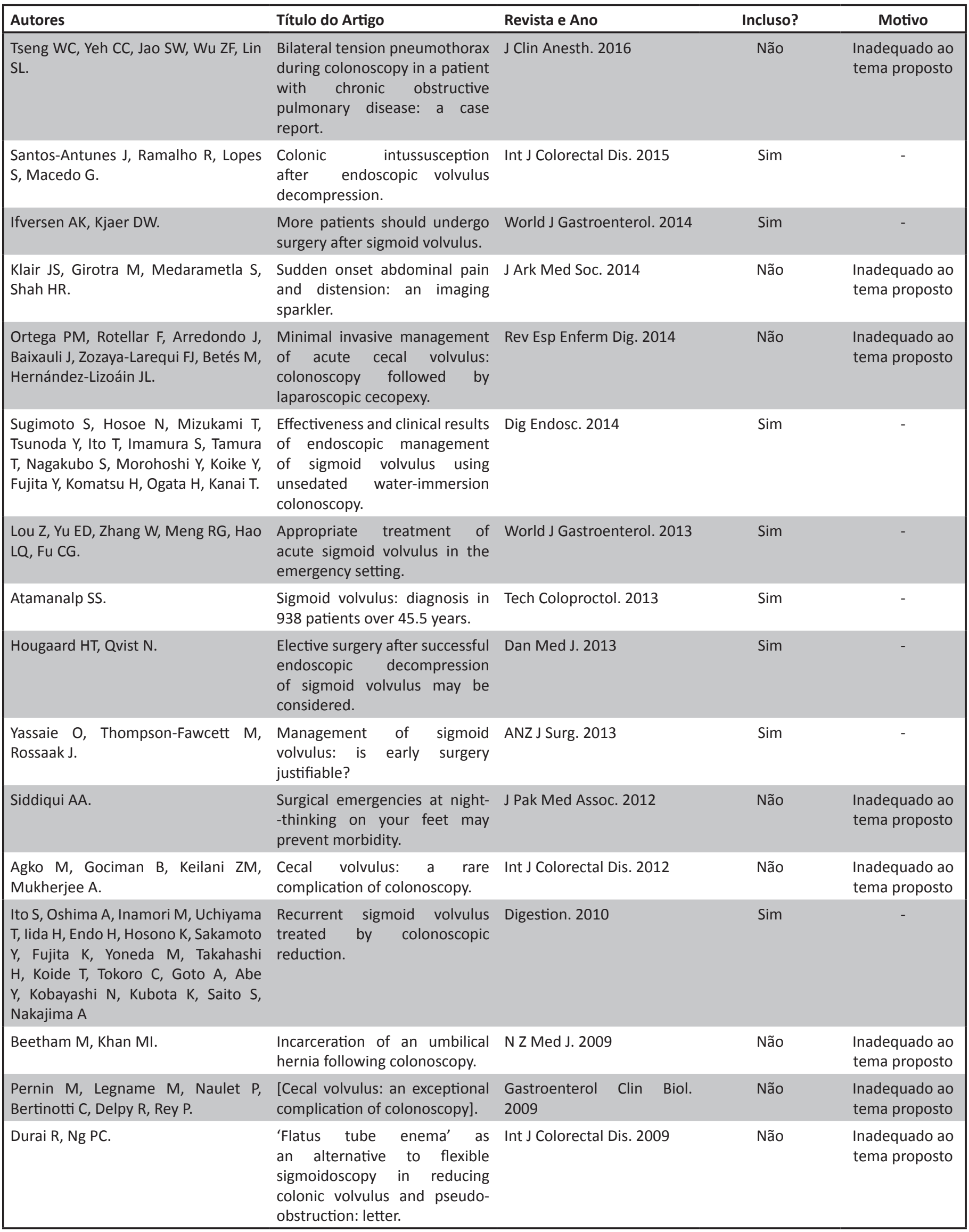




\begin{tabular}{|c|c|c|c|c|}
\hline Autores & Título do Artigo & Revista e Ano & Incluso? & Motivo \\
\hline Chu EC, Tarnawski AS. & $\begin{array}{l}\text { Rapid colonoscopic detection } \\
\text { and quantification of } \\
\text { colonic ischemia by using a } \\
\text { laser Doppler flowmeter. }\end{array}$ & Gastrointest Endosc. 2007 & Não & $\begin{array}{l}\text { Inadequado ao } \\
\text { tema proposto }\end{array}$ \\
\hline $\begin{array}{l}\text { Cowlam S, Watson C, Elltringham M, } \\
\text { Bain I, Barrett P, Green S, Yiannakou Y. }\end{array}$ & $\begin{array}{l}\text { Percutaneous endoscopic } \\
\text { colostomy of the left side of the } \\
\text { colon. }\end{array}$ & $\begin{array}{l}\text { Gastrointest } \\
\text { Endosc. } 2007\end{array}$ & Sim & - \\
\hline $\begin{array}{l}\text { Kim G, Jang EC, Kim YS, Yoon SA, Kim } \\
\text { SS, Yoo SJ, Chang YS, Kim YO. }\end{array}$ & $\begin{array}{l}\text { Sigmoid } \\
\text { volvulus occurring during bowel } \\
\text { preparation period before } \\
\text { colonoscopy in a } \\
\text { hemodialysis patient. }\end{array}$ & Clin Nephrol. 2006 & Não & $\begin{array}{l}\text { Inadequado ao } \\
\text { tema proposto }\end{array}$ \\
\hline $\begin{array}{l}\text { Tsai MS, Lin MT, Chang KJ, Wang SM, } \\
\text { Lee PH. }\end{array}$ & $\begin{array}{l}\text { Optimal interval from } \\
\text { decompression to semi-elective } \\
\text { operation in sigmoid volvulus. }\end{array}$ & $\begin{array}{l}\text { Hepatogastroenterology. } \\
2006\end{array}$ & Não & $\begin{array}{l}\text { Inadequado ao } \\
\text { tema proposto }\end{array}$ \\
\hline Kersting HW, Jähne J, Mai P. & $\begin{array}{l}\text { Volvulus of the small intestine, } \\
\text { a rare } \\
\text { complication during laxative } \\
\text { period before colonoscopy }\end{array}$ & $\begin{array}{l}\text { Dtsch Med Wochenschr. } \\
2004\end{array}$ & Não & $\begin{array}{l}\text { Inadequado ao } \\
\text { tema proposto }\end{array}$ \\
\hline $\begin{array}{l}\text { Turan M, Sen M, Karadayi K, Koyuncu } \\
\text { A, Topcu O, Yildirir C, Duman M. }\end{array}$ & $\begin{array}{l}\text { Our } \\
\text { sigmoid colon volvulus } \\
\text { experience and benefits of } \\
\text { colonoscope in detortion } \\
\text { process. }\end{array}$ & Rev Esp Enferm Dig. 2004 & Sim & - \\
\hline
\end{tabular}

\section{DISCUSSÃO}

Desde a introdução da distorção endoscópica na década de 1940, essa abordagem, juntamente com a ressecção subsequente, tornou-se a principal modalidade terapêutica ${ }^{1}$. Bruusgaard introduziu o uso da descompressão por sigmoidoscopia do volvo sigmoide em 1947, e esse continua sendo o método mais utilizado para o manejo conservador16. A taxa de sucesso é de cerca de $80 \%$ na primeira tentativa de descompressão ${ }^{7,19}$. 0 objetivo da distorção endoscópica é esvaziar, completamente, a área do cólon sigmoide para o reto. As fezes aquosas, quando macias, podem ser evacuadas sem a necessidade de orientação fluoroscópica ${ }^{35,36}$.

As taxas de complicação relatadas são inferiores a $2,5 \%$, com mortalidade inferior a $1 \%$, o que explica a popularidade da sigmoidoscopia rígida. As principais desvantagens desse método foram os poucos casos em que se perderam o diagnóstico de gangrena intestinal e a taxa mais alta de perfuração em comparação com o sigmoidoscópio flexível ${ }^{35,36}$. A distorção com colonoscopia completa também é utilizada no manejo do volvo sigmoide com o benefício adicional da visualização completa do cólon sigmoide, permitindo, assim, que os clínicos diferenciem o intestino viável e não viável. A literatura sugere que a colonoscopia também permite a identificação de outras patologias colônicas e pode ter uma maior taxa de sucesso 7,19 .
A distorção pode ser realizada por meio do enema de bário, proctoscopia rígida, sigmoidoscopia flexível ou colonoscopia, com ou sem colocação de tubo retal ${ }^{1,37,38}$. Após a descompressão do volvo do sigmoide, um tubo retal geralmente é inserido para "manutenção" para evitar a recorrência precoce. Os estudos variam em sua recomendação para a duração da inserção do tubo retal, de qualquer tempo entre 2 e 4 dias $^{7,19}$.

O exame endoscópico permite o diagnóstico por visualização da área do segmento torcido e também é valioso para a avaliação da viabilidade da mucosa. Em um vasto estudo de S. S. Atamanalp $(2014)^{3}$, com 998 pacientes, entre 1966 a 2012, o enema de bário foi bem sucedido em 9 de 13 pacientes (69,2\%). Dos 660 pacientes submetidos à distorção endoscópica, o procedimento foi bem sucedido em 510 pacientes (77,3\%). Dos 673 pacientes tratados não cirurgicamente, 37 (5,5\%) apresentaram sinais endoscópicos de gangrena intestinal e foram submetidos à cirurgia imediata, $117(17,4 \%)$ tiveram insucesso na distorção com necessidade de cirurgia de emergência, 23 (3,4\%) tiveram recorrência precoce do VS e foram submetidos à cirurgia imediata, 5 (0,7\%) morreram, enquanto 491 (73,0\%) não sofreram nenhum outro tratamento de emergência após a distorção endoscópica bem-sucedida ${ }^{3}$. 
Além disso, os enemas de contraste solúveis em bário ou solúveis em água podem mostrar o lúmen obstrutivo como uma terminação semelhante ao bico, mas essa abordagem não é usada se houver evidência ou suspeita de gangrena intestinal, perfuração ou peritonite ${ }^{17,22}$. Alternativamente, ao uso de enemas de contraste, a ultrassonografia Doppler e a fluxometria laser doppler podem ser úteis para predizer isquemia intestinal ou gangrena ao invés de diagnosticar $\mathrm{VS}^{3,4}$.

A taxa de sucesso para a descompressão sigmoidoscópica está entre $79 \%$ e $81 \%{ }^{38,39}$. Alguns relatórios revelam melhores resultados com uma abordagem flexíve ${ }^{11}$. Foi relatado que $24 \%$ das abordagens sigmoidoscópicas não encontrarão o local da torção, incentivando o uso da colonoscopia40. No geral, a descompressão foi bem sucedida em 70 a $80 \%$ dos $\operatorname{casos}^{1,9}$. A condição tem tendência a se repetir em $45-71 \%$ dos pacientes tratados de forma conservadora40, com mortalidade de $7 \%^{19}$; portanto, os clínicos recomendam que os pacientes sofram ressecção sigmoide, seja com anastomose primária ou com o procedimento de Hartmann. Ambas as cirurgias podem ser feitas como procedimentos de emergência, semieletivamente, durante a primeira admissão do paciente, ou como procedimentos eletivos durante a readmissão. Apesar da alta taxa de recorrência sem cirurgia, até $65 \%$ dos pacientes não sofrem uma ressecção profilática após a primeira incidência de volvulo sigmóide ${ }^{19,38,39}$. Se gangrena intestinal for encontrada, o paciente deve ser levado para a exploração e ressecção de caráter emergencial. Se a distorção for bem-sucedida, mas não for encontrada isquemia ou intestino gangrenoso, um tubo retal é deixado e a ressecção eletiva deve ser agendada. Deve-se ter cuidado na seleção de pacientes para distorção endoscópica. Pacientes com sinais e sintomas de sepse, febre, leucocitose e peritonite devem ser levados diretamente para a sala de operação (SO) para exploração ${ }^{1}$.

O tratamento inicial do volvo sigmoide agudo e não estrangulado é inserir um rectosigmoidoscópio rígido e tentar a passagem de um tubo macio e flexível através do segmento torcido. Mas esse procedimento tem um alto risco de perfuração. Ainda assim, os procedimentos de distorção para a série de Turan et al. (2004) foram realizados com um rectosigmoidoscópio rígido $(n=24)$ até 1994. Esses autores tiveram três casos em que ocorreu uma perfuração do cólon, e a taxa de sucesso foi baixa (42\%). No entanto, nos últimos sete anos, esse procedimento foi realizado com o auxílio de um colonoscópio $(n=15)$ e não houve complicações relacionadas a esse procedimento, enquanto a taxa de sucesso aumentou para $60 \%$. O colonoscópio flexível trouxe vantagens consideráveis ao diagnóstico e ao tratamento não cirúrgico do volvulus, pois sua propriedade de alimentação de ar e flexibilidade ajudam os clínicos na fase de detorção. Um colonoscópio também dá a chance de visualizar os segmentos proximais do cólon antes da cirurgia e evita que possíveis condições concomitantes sejam perdidas. O melhor potencial de visualização de um colonoscópio também é útil para o clínico quando se tenta diferenciar um intestino viável de um não viável $^{11}$.

A laparotomia deve ser realizada se houver uma mucosa ulcerada ou necrótica na endoscopia, ou se o intestino está inadvertidamente danificado. Taxas de recorrência de 30-90\% após reduções não operacionais de um vólvulo de sigmoide foram relatadas anteriormente. De acordo com relatórios anteriores, deixando um tubo retal no reto durante mais de 48-72 horas, e uma ressecção eletiva do cólon no prazo de 1 a 10 dias são medidas necessárias ${ }^{41}$. Turan et al $^{11}$ concluíram que uma terapia inicial com endoscopia proporciona descompressão e uma preparação adequada de pacientes para ressecção cirúrgica e que um colonoscópio flexível possui vantagens notáveis em relação aos instrumentos rígidos no processo de distorção.

A distorção não operatória é defendida como a principal opção de tratamento em vólvulo sigmoide agudo sem complicações. Embora os tubos rectais, os enemas de bario ou a sigmoidoscopia rígida tenham sido amplamente utilizados, a sigmoidoscopia flexível é agora o procedimento não operatório preferido. 0 tratamento não operatório é bem sucedido em $70-91 \%$ dos casos, com taxas de complicações relatadas de $2-4,7 \%$ em pacientes geriátricos ${ }^{20,42}$. No entanto, Lou et al. (2013)6 tiveram uma taxa de sucesso da distorção colonoscópica de 92,9\%. Neste estudo, cirurgia de emergência foi realizada em uma mulher de 41 anos em quem a colonoscopia não teve êxito. Um homem de 90 anos que não recebeu distorção e foi submetido à cirurgia imediata devido a uma perfuração com tecido adiposo incrustado a $50 \mathrm{~cm}$ da borda do ânus. Não houve mortalidade ou morbidade no grupo de tratamento coloscópico. Um dos dois pacientes do grupo de tratamento cirúrgico morreu.

A distorção coloscópica foi seguida de recorrência de 26,9\% nos pacientes de Lou et al. $(2013)^{6}$. Esses pacientes foram submetidos à distorção colonoscópica repetida com sucesso, sem mortalidade ou morbidade. Esses resultados sugerem que a colonoscopia é a principal escolha no tratamento do vulvulo sigmoide recorrente, particularmente em pacientes idosos que recusam a cirurgia eletiva.

Lou et al. (2013)6 concluíram que a descompressão e derotação colonoscópica é o principal tratamento de emergência de escolha no vólvulo sigmoide agudo não complicado e é uma modalidade de tratamento seguro para volvulus sigmoides recorrentes. A cirurgia de emergência é reservada para a gangrena e a descompressão falhada, em pacientes com alta taxa de recorrência, pode ser prudente considerar um intervalopara ressecção semi-eletiva e anastomose primária vários dias após a descompressão bem-sucedida ${ }^{6}$.

Em comparação com a sigmoidoscopia, a colonoscopia, além de uma taxa de sucesso superior e perfil de segurança é de comprimento adequado para alcançar o segundo ponto de constrição. Também permite uma melhor visualização da mucosa colônica e pode orientar o procedimento de descompressão e distorção. A sucção colonoscópica do cólon proximal facilita a recuperação rápida pela remoção de toxinas bacterianas. Além disso, Lou et al. (2013) adotaram uma colonoscopia de duplo funcionamento modificada que pode ajudar a minimizar o risco de perfuração. Distorção colonoscópica simplesmente converte 
uma emergência em um procedimento eletivo, o que facilita o tratamento da comorbidade e permite a preparação do intestino antes da cirurgia definitiva. Os resultados de Lou et al. (2013) sugerem que a colonoscopia é uma modalidade de tratamento segura e efetiva para vólvulo sigmoide agudo. Após a distorção, a lesão de isquemia-reperfusão agrava a disfunção intestinal e até a úlcera intestinal e a perfuração. O exsudato peritoneal, a acumulação de alto teor de fluído intestinal, distúrbios eletrolíticos e hipoproteinemia levam a consequências adversas graves. Consequentemente, o tratamento efetivo, após distorções colonoscópicas, é muito importante. A ressuscitação de líquidos deve ser realizada imediatamente. A terapia com vasodilatadores deve continuar, pois o uso desses agentes pode melhorar a microcirculação do tecido intestinal. Os antibióticos de amplo espectro são indicados para controlar a translocação bacteriana através da parede intestinal isquêmica ${ }^{6}$.

Seja qual for a técnica, uma vez que o ponto de torção foi passado, o cirurgião deve esperar uma queda de fezes e gás. Nesse ponto, um tubo retal deve ser colocado para evitar recorrência e segurar no lugar. O paciente deve então ser ressuscitado, pois muitos serão desidratados e talvez tenham anormalidades eletrolíticas ${ }^{1}$.

Os pacientes, que falham na descompressão endoscópica, tiveram gangrena intestinal identificada na endoscopia ou que apresentam sinais e sintomas de sepse, devem ser preparados para cirurgia de forma imediata. O paciente deve ser ressuscitado, iniciado antibióticos de amplo espectro e não ingerir nada por via oral. Se o paciente é hemodinamicamente instável, nenhuma outra imagem ou testes devem ser ordenados e o paciente deve ir para a sala de operação. A exploração deve ser realizada em uma incisão na linha média. Uma vez identificado o vólvulo, deve ser avaliado quanto à viabilidade. Se o intestino parecer saudável ou apenas ligeiramente comprometido, pode ser reduzido e as opções cirúrgicas acima mencionadas podem ser consideradas ${ }^{1}$.

A cirurgia de emergência está associada à mortalidade e morbidade significativas. Kassi et $a^{43}$ relataram que a taxa de mortalidade foi de $12 \%(n=3)$ para o procedimento de Hartmann. As infecções do local cirúrgico (42,86\%) foram as complicações mais comuns. Onze (50\%) de 22 pacientes tiveram continuidade intestinal restaurada. Bhatnagar et $\mathrm{al}^{44}$ relataram que os fatores de risco para a mortalidade foram (1) idade acima de 60 anos; (2) presença de choque na admissão; e (3) história positiva de um episódio anterior de volvulo6.

Em um artigo original, a distorção de vólvulo pré-operatória endoscópica foi tentada em todos os pacientes ${ }^{11}$. Em 19 dos 39 pacientes que não foram distorcidos cirurgicamente, uma ressecção sigmoide com anastomose primária foi realizada dentro de 7-10 dias após a redução, no entanto 20 pacientes não aceitaram uma operação eletiva após o tratamento não operatório. Embora nenhum seguimento regular tenha sido feito, três desses casos apresentaram recorrência e cirurgia ${ }^{11}$.

Em um estudo de pacientes em hospitais de "Veterans Affairs", a taxa de mortalidade foi de $24 \%$ para aqueles que se submeteram a operações de emergência para vólvulo sigmoide, contra $6 \%$ para procedimentos eletivos com descompressão antecedente. A mortalidade foi correlacionada com a cirurgia emergente $(p<0,01)$ e o cólon necrótico $(p<0,05)^{46} .5 \mathrm{Em}$ grandes séries da Turquia, a mortalidade global para pacientes com vólvulo sigmoide foi de $15,8 \%$, enquanto a taxa de complicações foi de $37,2 \%$. Em pacientes com gangrena intestinal, foram encontradas taxas de mortalidade semelhantes à anastomose primária versus o procedimento de Hartmann de $21,6 \%$ versus $19,2 \%$, respectivamente. No entanto, quando combinado com a limpeza colônica operatória, a taxa de mortalidade para anastomose caiu para $9,3 \%{ }^{16}$.

Atualmente, o tratamento endoscópico emergente é considerado um remédio temporário que deve ser seguido, na maioria dos casos, por cirurgia eletiva definitiva, com ressecção do cólon sigmoide redundante sendo o procedimento padrãoouro. Embora o tratamento endoscópico seja eficaz, também está associado a uma alta taxa de recorrência (18-90\%), e a taxa de mortalidade por recorrência é de 5-35\% ${ }^{4} .12$ Uma vez que os sintomas imediatos foram aliviados, recomenda-se o tratamento cirúrgico eletivo (dispensando pacientes de alto risco) dentro de 48-72 h, após a distorção do VS $\mathrm{V}^{1,35,46}$.

O manejo conservador do vólvulo sigmoide com descompressão é claramente o tratamento preferido para os pacientes que não são aptos para a cirurgia. À luz das altas taxas de recorrência, parece razoável considerar a cirurgia para o restante ${ }^{7,16,18,19}$.

Yassaie et al (2012) ${ }^{7}$ demonstraram uma alta taxa de recorrência para pacientes com volvulus sigmoide tratado de forma conservadora. Essas descobertas sustentam um papel para a cirurgia eletiva precoce em pacientes com vólvulo sigmoide agudo que são um risco operacional razoável.

O estudo de Yassaie et al $(2012)^{7}$ demonstra que a cirurgia eletiva pode ser realizada com baixa morbidade e mortalidade, mesmo após recidivas múltiplas em pacientes tratados inicialmente de forma conservadora ${ }^{7}$. Dos 12 pacientes tratados de forma conservadora, cinco (42\%) representaram a uma mediana de 4,8 meses com volvulus recorrentes. Três desses pacientes exigiram colectomias de emergência e todos esses pacientes apresentaram complicações pós-operatórias, envolvendo infecções respiratórias $(n=2)$ e de íleo $(n=1)$. Um total de 39 dos 57 pacientes necessitaram de cirurgia no período de estudo. Houve dois casos que foram feitos de forma laparoscópica?.

Atualmente, não há diretrizes internacionais que recomendam quando operar a descompressão pós-tratamento conservador. Hospitais oferecem cirurgia entre 2 há 30 dias 2,8 após descompressão conservadora. Uma abordagem razoável podese oferecer cirurgia eletiva na admissão inicial26. A questão de como logo após a descompressão sigmoidoscópica poderia ser oferecida cirurgia eletiva foi abordada por Tsai et al.46. No estudo de Yassaie et al $(2012)^{7}$, não houve diferença em complicações ou mortalidade entre os pacientes que tiveram cirurgia em 2 dias e mais de 2 dias, após a descompressão, indicando que 2 
dias poderiam ser adequados para a preparação de pacientes para cirurgia.

Helene Tarri Hougaard e Niels Qvist (2013) $)^{30}$ em um artigo original com 41 pacientes em um período de 11 anos, inicialmente, conseguiram descomprimir $97 \%$ dos pacientes com endoscópio flexível. Esta é uma taxa elevada em comparação com outros estudos $(50-90 \%)^{4}$, mas muitos dos estudos anteriores não distinguiram entre escopos flexíveis e rígidos. Existe uma alta taxa de recorrência após a descompressão endoscópica, em alguns estudos até $90 \%{ }^{15}$. Em seu estudo, a taxa de recorrência foi de $82 \%$. Foram relatadas altas taxas de gangrena intestinal na recorrência do vólvulo e com altas taxas de mortalidade e morbidade ${ }^{15}$.

Helene Tarri Hougaard e Niels Qvist (2013) $)^{30}$ descobriram que houve uma alta taxa de mortalidade de 30 dias (43\%) para aqueles que foram submetidos à cirurgia aguda. Essa taxa foi, significativamente, maior do que a taxa de mortalidade de 30 dias observada no grupo de cirurgia eletiva (8\%). A taxa de mortalidade no grupo eletivo é comparável àquelas relatadas na literatura. No entanto, no grupo de cirurgia aguda, a taxa deles foi maior do que as taxas relatadas por outros que variam de $7-42 \%^{31}$. Isso pode ser explicado pelo fato de que a maioria dos estudos é conduzida em áreas endêmicas em que a seleção do paciente pode influenciar. Assim, neste estudo, houve uma alta frequência de gangrena intestinal associada a uma alta taxa de mortalidade ${ }^{31}$.

A taxa de mortalidade de 30 dias no grupo de pacientes tratados de forma conservadora foi de 14\%, o que é comparável às taxas relatadas por outros estudos ${ }^{15}$, e após um ano, a taxa de mortalidade foi de 50\%. Helene Tarri Hougaard e Niels Qvist $(2013)^{30}$ não foram capazes de investigar os motivos da alta taxa de mortalidade após um ano, mas a recorrência do volvo pode explicar isso. A diferença entre os três grupos de acordo com as taxas de mortalidade de um ano não foi significativa. A pequena população de estudo pode explicar esse achado.

Embora a população, no estudo de Helene Tarri Hougaard e Niels Qvist $(2013)^{30}$, tenha consistido em pacientes idosos com alto grau de comorbidade, os resultados mostraram que a cirurgia eletiva, após a primeira recorrência, deveria ser considerada. Isto é devido à alta taxa de mortalidade de um ano no grupo não cirúrgico, as altas taxas de mortalidade no grupo de cirurgia aguda e a baixa taxa de mortalidade no grupo de cirurgia eletiva. Esta conclusão está em conformidade com as recomendações feitas em outros estudos ${ }^{15,39}$. Este estudo e outros mostraram que a comorbidade existente não deve ser dada como o motivo para excluir pacientes da cirurgia ${ }^{30}$.

Em conclusão, os resultados de Helene Tarri Hougaard e Niels Qvist $(2013)^{30}$ apoiam a recomendação de cirurgia eletiva após descompressão endoscópica bem-sucedida do vólvulo sigmoide, mesmo em casos com morbidade significativa. Embora a evidência seja relativamente fraca e com base em estudos retrospectivos, a condução de estudos prospectivos randomizados parece pouco realista.
Yassaie et al $(2012)^{7}$ calcularam curvas de sobrevivência para avaliar a longevidade dos pacientes tratados de forma conservadora em comparação com aqueles tratados cirurgicamente. Embora haja queda nos primeiros 12 meses naqueles pacientes, inicialmente, manejados de forma conservadora, não há desvantagem de sobrevivência aparente no tratamento conservador. Os pacientes, com tratamento conservador na admissão de índice provavelmente, terão maiores comorbidades, mas não parecem ter uma sobrevida significativamente pior.

A principal descoberta do estudo de Ifversen \& Kjaer (2014) ${ }^{38}$ é que os pacientes tratados com cirurgia tiveram uma taxa de sobrevivência significativamente melhor do que os pacientes tratados de forma conservadora. Além disso, eles descobriram que mais da metade dos pacientes tratados de forma conservadora experimentaram uma recorrência de seu volvo sigmoide nos primeiros 5 meses. Isso sugere que os pacientes devem ser tratados com cirurgia após a primeira incidência de volvo sigmoide, a menos que comorbidade severa proíba ou cirurgia de emergência seja necessária.

O grupo de tratamento conservador no estudo de Ifversen \& Kjaer $(2014)^{38}$ teve uma mortalidade de 30 dias de 15\% (4/26) em comparação com 9-36\% relatados em outros estudos19,39. Eles descobriram que a mortalidade de 30 dias para os pacientes com tratamento conservador e cirúrgico era quase a mesma, no entanto, o prognóstico e a sobrevivência para pacientes que tiveram cirurgia foram consideravelmente melhores ao longo prazo em comparação com os pacientes tratados de forma conservadora. Uma explicação poderia ser que os 2 grupos eram diferentes em idade mediana e na média do índice ASA. Apesar disso, 8 dos 14 pacientes tratados de forma conservadora com recorrência, todos idosos e com alto índice de ASA, foram submetidos à cirurgia sem mortalidade de 30 dias. Nem o grupo Ifversen \& Kjaer (2014)38, nem Tan et al19 e Larkin et al39 encontraram mortalidade entre os pacientes submetidos à cirurgia após a recorrência. Isso indica que a melhor sobrevivência, em longo prazo, para pacientes tratados cirurgicamente não pode ser explicada exclusivamente por diferenças nos níveis de idade e ASA e indica que mais pacientes poderiam ter sido submetidos à cirurgia durante a primeira admissão ${ }^{38}$.

O manejo de pacientes idosos e debilitados é extremamente difícil. O VS ocorre mais comumente em pacientes idosos, particularmente em pacientes psiquiátricos ou em pessoas com demência. A mortalidade aumenta após a idade de 70 anos porque $50-85 \%$ dos pacientes desenvolvem comorbidades graves após a cirurgia ${ }^{4,47}$. A controvérsia em torno das indicações para cirurgia eletiva é baseada no alto risco cirúrgico para esses pacientes; A cirurgia eletiva tem uma taxa de mortalidade de $16 \%$, enquanto a taxa de mortalidade causada pela recorrência é de $9 \%$. Além disso, após a distorção endoscópica inicial, 83\% dos pacientes morreram dentro de dois anos de outras doenças que não o VS recorrente. A mortalidade geral para VS, que, anteriormente, era superior a $50 \%$, caiu para bem abaixo de $10 \%{ }^{4}$. É relatado que a proporção de pacientes com necrose 
intestinal chega a $60 \%$ em casos recorrentes em comparação com $6 \%$ durante o primeiro episódio de $\mathrm{VS}^{47}$, enquanto nenhum dos pacientes com VS recorrente desenvolveu necrose intestinal. Isso sugere que o diagnóstico precoce e o tratamento endoscópico podem reduzir o risco de necrose colônica. No estudo de Turan et $\mathrm{al}^{35}$, a recorrência da distorção endoscópica foi relativamente alta (56\% por paciente e $75 \%$ por procedimento). No entanto, na maioria dos casos deste estudo, a ressecção do cólon sigmoide envolvido foi evitada. Assim, em pacientes de alto risco e idosos, a retorsão endoscópica repetida é considerada uma opção terapêutica para evitar a cirurgia de alto risco ${ }^{35}$.

Liang reportou que os pacientes que apresentaram vólvulo sigmóide e foram submetidos à distorção e à preparação intestinal foram tratados com sucesso com ressecções sigmoides laparoscópicas ${ }^{48}$. Outra série pequena feita por CartwrightTerry também encontrou que uma abordagem laparoscópica do volvo sigmoide é segura após a distorção ${ }^{49}$.

Para os pacientes tratados de forma conservadora durante a primeira admissão, volvo recorrente provavelmente viria a ocorrer nos meses a seguir. A literatura relata taxas de recorrência de $45-71 \%$, dependendo da duração do seguimento ${ }^{19,39}$. Menos da metade dos pacientes de Ifversen \& Kjaer $(2014)^{38}$ tratados de forma conservadora foram livres de recorrência após 6 meses. Além disso, de acordo com a análise por curva de Kaplan-Meier, apenas 24\% não experimentaram recorrência após dois anos. Deve-se notar que esse grupo de pacientes foi considerado incapaz de se submeter a uma ressecção sigmoide ou se recusou a submeter-se a esse procedimento. Pode muito bem ser que muito poucos desses pacientes foram encorajados a serem submetidos à cirurgia durante a primeira admissão. 0 fato de que a mortalidade de 30 dias foi zero no pequeno grupo de pacientes que foi operado quando teve uma recorrência indica que esse encorajamento seria apropriado ${ }^{38}$.

Algumas técnicas, ainda não bem validadas na literatura, já mostraram resultados promissores no tratamento endoscópico do volvo de sigmoide, como é o caso da colonoscopia por Water-immersion, que reduz o desconforto do paciente e não requer sedação durante o procedimento ${ }^{50}$. A principal razão para a efetividade do tratamento é a redução do comprimento e da angulação do colón sigmoide ${ }^{35,51}$.

A técnica de colonoscopia por imersão em água foi utilizada em 21 pacientes em um artigo original de Sugimoto et al. (2014) $)^{35}$. Em primeiro lugar, a distorção endoscópica foi testada em pacientes sem contraindicações para terapia endoscópica, como aqueles sem peritonite, instabilidade hemodinâmica, isquemia intestinal ou perfuração. A colonoscopia de imersão em água não requer preparo intestinal completo; eles usaram irrigação do cólon e um colonoscópio com um sistema de jato de água (PCF tipo Q 260J, Olympus Medical Systems, Tóquio, Japão). Se o distorsionamento foi bem sucedido e a necrose estava ausente, os pacientes, muitas vezes, não eram internados. Se a mucosa fosse necrótica e gangrenosa, o processo era abortado. Uma avaliação completa e detalhada da mucosa não era tipicamente necessária, permitindo um foco na distorção, descompressão do segmento distendido e exclusão da necrose.

Combinação da técnica de imersão em água e o gancho distal transparente tornaram o procedimento fácil e seguro. Com essa combinação, quase todo o ar pode ser aspirado e a vista endoscópica foi mantida pelo espaço dentro do gancho preenchido com uma pequena quantidade de água limpa. A sedação e outros medicamentos, como anticolinérgicos e analgésicos, não foram utilizados ${ }^{35}$.

A abordagem primária de Sugimoto et al. (2014) $)^{35}$ para pacientes clinicamente estáveis com VS envolve procedimentos endoscópicos de distorção. Se o tratamento endoscópico for ineficaz ou se o paciente desenvolver sinais de peritonite, a cirurgia emergente é indicada. A distorção endoscópica inicial foi realizada com sucesso em todos os 21 pacientes. Não houve complicações, como a perfuração do cólon e nenhuma queixa de dor abdominal relacionada ao procedimento. Sete dos 21 pacientes não foram sequer hospitalizados e foram capazes de voltar para casa após o procedimento. Esses resultados sugerem que o manejo endoscópico de VS, usando colonoscopia de água e imersão é seguro e viável ${ }^{35}$.

Como a dor durante a colonoscopia indica risco de perfuração intestinal e a sedação mascara este importante sinal de alerta, uma técnica de inserção indolor é essencial para a segurança do paciente ${ }^{50}$. Durante a fase de inserção da colonoscopia, a infusão de água, em vez da insuflação de ar tradicional, foi proposta para reduzir a dor e melhorar a aceitação pelo paciente do procedimento. A colonoscopia de imersão em água também minimiza a distensão do colón e melhora a visibilidade, permitindo a remoção completa do ar quando a ponta do colonoscópio está no rectosigmoide. Essas manobras endireitam o retosigmoide e permitem que o colonoscópio seja inserido ainda mais sem causar uma volta no cólon ${ }^{50,51}$. Assim, a colonoscopia de imersão em água é considerada um procedimento apropriado para a distorção. Além disso, é também um método relativamente simples para os treinandos, como relatado anteriormente $\mathrm{e}^{35,52}$.

As limitações de Sugimoto's et al. (2014) ${ }^{35}$ foram o pequeno número de sujeitos envolvidos e a coleta retrospectiva de dados descritivos. Será necessário um tamanho de amostra maior e um estudo prospectivamente concebido para confirmar a eficácia deste método. Em conclusão, a experiência deles sugere que o tratamento endoscópico com colonoscopia de imersão em água é um procedimento eficaz e seguro para pacientes idosos com VS na ausência de achados necróticos.

O volvo sigmoide agudo é frequentemente encontrado na prática clínica. No entanto, nenhum relatório prévio descreveu o uso de um laço endoscópico para guiar a colocação de uma sonda (para permitir a drenagem ou instalação de substâncias) ou um cateter de medição sob visão direta. Piers Anthony Cheyne Gatenby e Colin Elton (2006) ${ }^{53}$ empregaram um novo método para a colocação de um tubo sob visão direta por "laçamento" de um fio de enxofre endoscópico (passado pelo colonoscópio) 
na extremidade do tubo. O paciente recebeu dieta completa após o procedimento e recebeu alta hospitalar no terceiro dia. Sugere-se que essa técnica possa obter resultados satisfatórios no tratamento do vulvo sigmoide agudo ${ }^{53}$.

Cowlam et al (2005) ${ }^{54}$, em um artigo original com 27 pacientes, impediram o volvo sigmoide recorrente e controlaram, efetivamente, os sintomas por uma inserção de tubo de colostomia endoscópica percutânea (CEP). O CEP é um procedimento endoscópico minimamente invasivo em que um tubo plastificado é inserido no lado esquerdo do cólon. Com isso, o intestino pode ser irrigado ou descomprimido. A inserção de CEP também foi usada para consertar o cólon sigmoide da parede abdominal em volvo sigmoide recorrente, oferecendo, assim, uma alternativa à sigmoidopexia ou à ressecção cirúrgica55,56. Os relatórios anteriores sugerem um resultado satisfatório, com boa eficácia e poucas complicações ${ }^{54,57}$.

Resultados promissores foram relatados em estudos após a inserção de tubos CEP $^{19,54}$, colocados com o auxílio de um colonoscópio. Aspectos importantes do sucesso terapêutico são a distorção, a descompressão e a fixação. Um de dois pacientes tratados com inserção de CEP, por Ifversen \& Kjaer $(2014)^{38}$, a distorção colonoscópica do cólon sigmoide não foi alcançada, o que pode ser uma razão para a morte precoce desse paciente. Outros estudos relataram uma mortalidade bastante baixa após este procedimento $(0-5 \%)^{19,54}$, por isso pode ser aconselhável oferecer inserção de tubo CEP a pacientes que, de outra forma, seriam tratados de forma conservadora, pois pode melhorar a sobrevida e diminuir o risco de recorrência ${ }^{38}$.

Ifversen \& Kjaer (2014) ${ }^{38}$ concluíram que, se houver suspeita de gangrena ou perfuração, pacientes com volvo sigmoide devem ser submetidos a cirurgia de emergência. Caso contrário, eles devem sofrer descompressão sigmoidoscópica de emergência e ser recomendados para cirurgia se sua condição geral o permitir. A alta taxa de recorrência em pacientes com tratamento conservador indica que mais pacientes devem ser encorajados a sofrer ressecção cirúrgica ou inserção de CEP.

O tratamento não cirúrgico para o volvo cecal via endoscopia é geralmente considerado limitado e relativamente ineficaz. As taxas de sucesso foram relatadas em $30 \%$. Dado a taxa mais alta de isquemia, ineficácia e dificuldade técnica com endoscopia, a colonoscopia geralmente não é recomendada, e o manejo cirúrgico deve ser a principal modalidade. Os achados na laparotomia ditarão o curso cirúrgico. Inicialmente, a viabilidade do intestino deve ser avaliada. Se gangrena é encontrada, o que pode ocorrer em 23 a 100\% dos casos, a ressecção é obrigatória. Se a capacidade de cura do paciente for comprometida por comorbidades, como desnutrição, anemia, uso crônico de esteroides ou outras condições, ressecção com ileostomia deve ser realizada. Se o cirurgião encontrar um intestino viável, a ressecção nem sempre é necessária. A distorção do intestino é possível; no entanto, as taxas de recorrência podem atingir 25 a 70\%. Outras técnicas incluem distorção e cecopexia e/ou colocação de um tubo de cecostomia ${ }^{1}$.
Embora a descompressão endoscópica seja possível com o volvo do cólon transversal e de flexura esplênica, o risco de recorrência e a dificuldade de desorção tornam-se ineficazes e possivelmente uma modalidade perigosa. Manejo cirúrgico inclui destorção, com ou sem colopexia ou ressecção. Como outras formas de volvo, se o gangrena for encontrada, a ressecção é obrigatória. E nos casos em que seja encontrado intestino viável, dado o risco de recorrência, o consenso afirma que uma hemicolectomia direita estendida ou a colectomia transversal seja realizada ${ }^{1}$.

O alívio da obstrução e a prevenção da recorrência são os dois objetivos cardinais do manejo no volvo colônico ${ }^{31}$. A redução espontânea ocorre em $2 \%$ dos pacientes 28 . No entanto, o tempo não deve ser desperdiçado nessas imprevisíveis situações. Segundo uma revisão sistemática de Raveenthiran et al. (2010) $)^{59}$ a descompressão endoscópica, popularizada por Bruusgaard60, é o gerenciamento de emergência de escolha em VS sem complicações. Oren et al. ${ }^{16}$ encontram que a sigmoidoscopia rígida e flexível são igualmente eficazes, enquanto outros ${ }^{11}$ mostram que esse era mais eficaz e mais seguro.

A distorção endoscópica é seguida de recorrência em 18$90 \%$ dos casos e morte em 5-35\% ${ }^{16,31,39}$. Raveenthiran et al. $(2010)^{59}$ concluem que a redução endoscópica simplesmente converte uma emergência em uma situação eletiva, que facilita o tratamento de comorbidades e permite a preparação do intestino antes de cirurgia definitiva. É inestimável confirmar a viabilidade do cólon reduzido. Aspiração colonoscópica do cólon proximal facilita a recuperação rápida, eliminando toxinas bacterianas e melhorando a ventilação ${ }^{61}$. Menos de $3 \%$ de perfurações iatrogênicas relatadas no passado provavelmente estavam associadas à sigmoidoscopia rígida ${ }^{60}$.

Por meio de uma revisão sistemática, Raveenthiran et al. $(2010)^{59}$ afirmam que o consenso atual é realizar cirurgia definitiva, isentando pacientes de alto risco, dentro de dois dias da distorção inicial46,62,63. Recorrência de volvo, mesmo durante este período, não é incomum porque a descompressão endoscópica efetiva não é sinônima de sucesso de distorção ${ }^{64}$. Tais recorrências iniciais podem ser evitadas deixando um tubo de flatus in situ de preferência sob orientação endoscópica ${ }^{53,65}$.

\section{CONCLUSÃO}

A intervenção endoscópica inicial no volvo colônico agudo e não estrangulado parece ser vantajosa quando comparada aos outros métodos de intervenção. A colonoscopia apresentou melhores resultados na fase de distorção e descompressão, melhor visualização do cólon e melhor avaliação da viabilidade das alças intestinais quando comparado aos outros métodos terapêuticos. Apesar da alta recorrência após a distorção colonoscópica, a morbimortalidade dos pacientes submetidos a essa forma de manejo terapêutico foi considerada, em diversas séries, baixa em comparação com a terapêutica cirúrgica de emergência. 


\section{REFERÊNCIAS}

1. Gingold D, Murrell Z. Management of colonic volvulus. Clin Colon Rectal Surg. 2012 Dec; 25(4) :236-244. doi: 10.1055/s-0032-1329535.

2. Ballantyne GH. Review of sigmoid volvulus: history and results of treatment. Dis Colon Rectum 1982 Jul-Ago; 25(5):494-501.

3. Atamanalp SS. Sigmoid volvulus: diagnosis in 938 patients over 45.5 years. Tech Coloproctol. 2013 Aug;17(4):419-24. doi: 10.1007/s10151-012-0953-z.

4. Raveenthiran V, Madiba TE, Atamanalp SS De U. Volvulus of the sigmoid colon. Colorectal Dis 2010 Jul; 12 (7 Online):e1-17. doi: 10.1111/j.14631318.2010.02262.x

5. Atamanalp SS. Sigmoid volvulus. Eurasian J Med. 2010 Dec; 42(3): 142-147. doi: 10.5152/eajm.2010.39.

6. Lou Z, Yu ED, Zhang W, Meng RG, Hao LQ, Fu CG. Appropriate treatment of acute sigmoid volvulus in the emergency setting. World J Gastroenterol. 2013 Aug 14;19(30):4979-83. doi: 10.3748/wjg.v19.i30.4979.

7. Yassaie $O$, Thompson-Fawcett $M$, Rossaak J. Management of sigmoid volvulus: is early surgery justifiable? ANZ J Surg. 2013 Jan;83(1-2):74-8. doi: 10.1111/j.1445-2197.2012.06182.x.

8. Asbun H, Castelooanos H, Balderrama B, Ochoa J, Aismendi R, Teran H, et al. Sigmoid volvulus in the high altitude of the Andes: review of 230 cases. Dis. Colon Rectum 1992; 35(4): 350-3.

9. Hellinger MD, Steinhagen RM. Colonic volvulus. In: Beck DE, Rombeau JL, Stamos MJ, Wexner SD, eds. The ASCRS Textbook of Colon and Rectal Surgery. New York: Springer; 2009: 286-298.

10. Mulas C, Bruna M, García-Armengol J, Roig JV. Management of colonic volvulus. Experience in 75 patients. Rev Esp Enferm Dig 2010 Apr; 102(4): 239248.

11. Turan M, Sen M, Karadayi K, Koyuncu A, Topcu O, Yildirir C, et al. Our sigmoid colon volvulus experience and benefits of colonoscope in detortion process. Rev Esp Enferm Dig. 2004 Jan;96(1):32-5.

12. Almog Y, Dranitzki-Elhalel M, Lax E, Zimmerman J, Glaser B. Sigmoid volvulus presenting as chronic secretory diarrhea responsive to octreotide. Am J Gastroenterol. 1992 Jan; 87(1):148-150.

13. Connolly S, Brannigan AE, Heffeman E, Hyland JM. Sigmoid volvulus: a 10-year-audit. Ir J Med Sci. 2002 Oct-Dec; 171(4): 216-217.

14. Atamanalp SS, Keles MS, Aydinli B. Serum potassium levels in sigmoid volvulus. Eurasian J Med. 2009 Dec; 41(3): 143-145.

15. Atamanalp SS, Ozturk G. Sigmoid volvulus in the elderly: outcomes of a 43year, 453-patient experience. Surg Today 2011 Apr; 41(4): 514-519.

16. Oren D, Atamanalp SS, Aydinli B, Yildirgan MI, Basoglu M, Polat $\mathrm{KY}$, et al. An algorithm for the management of sigmoid colon volvulus and the safety of primary resection: experience with 827 cases. Dis Colon Rectum. 2007 Apr; 50(4): 489-497.

17. Ballantyne GH, Brandner MD, Beart RW Jr, Ilstrup DM. Volvulus of the colon. Incidence and mortality. Ann. Sur. 1985 Jul; 202(1): 83-92.

18. Heis HA, Bani-Hani KE, Rabadi DK, Elheis MA, Bani-Hani BK, Mazahreh TS, et al. Sigmoid volvulus in the Middle East. World J. Surg. 2008 Mar; 32(3): 459-64. doi: 10.1007/s00268-007-9353-3.

19. Tan K, Chong C. Management of acute sigmoid volvulus: an institution's experience over 9 years. World J. Surg. 2010 Aug; 34(8): 1943-8. doi: 10.1007/ s00268-010-0563-8.

20. Avots-Avotins KV, Waugh DE. Colon volvulus and the geriatric patient. Surg
Clin North Am 1982 Apr; 62(2): 249-260.

21. Mangiante EC, CroceMA, Fabian TC, Moore OF III, Britt LG. Sigmoid volvulus. A four-decade experience. Am Surg 1989 Jan; 55(1):41-44.

22. Wai CT, Lau G, Khor CJL (105) Clinics in diagnostic imaging. Singapore Med J. 2005 Out; 46(9): 483-487

23. Tsang TK, Siu KW, Lai A, Kwok PC, Chan S. Images of interest: sigmoid volvulus. J Gastroenterol Hepatol. 2005 May; 20(5):790. doi: 10.1111/j.14401746.2005.03934.x.

24. Slidell $M$, Samir SA, Feller ER. Sigmoid volvulus in three college-age teenagers. J Clin Gastroenterol. 2004 Nov-Dec; 38(10): 910-911.

25. Ballantyne GH. Sigmoid volvulus: high mortality in county hospital patients. Dis Colon Rectum 1981 Oct; 24(7):515-520.

26. Chung Y, Eu K, Nyam D, Leong A, Ho Y, Seow-Choen F. Minimizing recurrence after sigmoid volvulus. Br. J. Surg. 1999 Feb; 86(2): 231-3. doi: 10.1046/j.13652168.1999.01034.x

27. Starling JR. Initial treatment of sigmoid volvulus by colonoscopy. Ann Surg. $1979 \mathrm{Jul} ; 190(1): 36-39$.

28. Shepherd J. Treatment of volvulus of sigmoid colon: a review of 425 cases. Br. Med. J. 1968 Feb; 1(5587): 280-4. doi: 10.1136/bmj.1.5587.280.

29. Arnold G, Nancem F. Volvulus of the sigmoid colon. Ann. Surg. 1973 May; 177(5): 527-31. doi: 10.1097/00000658-197305000-00004.

30. Hougaard HT, Qvist N. Elective surgery after successful endoscopic decompression of sigmoid volvulus may be considered. Dan Med J. 2013 Jul; 60(7): A4660.

31. Madiba TE, Thomson SR. The management of sigmoid volvulus. J R Coll Surg Edinb. 2000 Apr; 45(2): 74-80.

32. Anderson JR, Lee $\mathrm{D}$. The management of acute sigmoid volvulus. Br J Surg. 1981 Feb; 68(2): 117-20. doi: 10.1002/bjs.1800680217.

33. Gupta SS, Singh O, Paramhans D, Mathur RK. Tube sigmoidostomy: a valuable alternative to sigmoidopexy for sigmoid volvulus. J Visc Surg. 2011 Apr; 148(2): e129-e133. doi: 10.1016/j.jviscsurg.2011.02.003.

34. Orchard JL, Mehta R, Khan AH. The use of colonoscopy in the treatment of colonic volvulus: three cases and review of the literature. Am J Gastroenterol 1984 Nov;79(11):864-867.

35. Sugimoto $\mathrm{S}$, Hosoe N, Mizukami T, Tsunoda $\mathrm{Y}$, Ito $\mathrm{T}$, Imamura $\mathrm{S}$, et al. Effectiveness and clinical results of endoscopic management of sigmoid volvulus using unsedated water-immersion colonoscopy. Dig Endosc. 2014 Jul; 26(4):564-8. doi: 10.1111/den.12235.

36. Sugimoto $\mathrm{S}$, Mizukami $\mathrm{T}$, Ito $\mathrm{T}$, Tsunoda $\mathrm{Y}$, Imamura $\mathrm{S}$, Tamura $\mathrm{T}$, et al. Endoscopic detorsion for sigmoid volvulus using unsedated water-immersion colonoscopy. Endoscopy 2013; 45(Suppl 2): E263-4.

37. Rokitansky C. Handbuch der Pathologischen Anatomie. Wien, Germany: Braumüller \&. Seidel; 1841

38. Ifversen AK, Kjaer DW. More patients should undergo surgery after sigmoid volvulus. World J Gastroenterol. 2014 Dec; 20(48):18384-9. doi: 10.3748/wjg. v20.i48.18384.

39. Larkin JO, Thekiso TB, Waldron R, Barry K, Eustace PW. Recurrent sigmoid volvulus - early resection may obviate later emergency surgery and reduce morbidity and mortality. Ann R Coll Surg Engl. 2009 Apr; 91(3): 205-209. doi:10.1308/003588409X391776. 
40. Brothers TE, Strodel WE, Eckhauser FE. Endoscopy in colonic volvulus. Ann Surg 1987 Jul; 206(1):1-4.

41. Oraja EA. Sigmoid volvulus in Kenyatta National Hospital. 1976- 1980. E Afr Med J 1983 May; 60(5): 290-6.

42. Bak MP, Boley SJ. Sigmoid volvulus in elderly patients. Am J Surg 1986 Jan; 151(1): 71-75. doi: 10.1016/0002-9610(86)90014-0.

43. Kassi AB, Lebeau R, Yenon KS, Katche E, Diane B, Kouassi JC. Morbidity and mortality of Hartmann's procedure for sigmoid volvulus at the University Hospital of Cocody, Abidjan. West Afr J Med. 2011.May-Jun; 30(3): 169-172.

44. Bhatnagar BN, Sharma CL, Gautam A, Kakar A, Reddy DC. Gangrenous sigmoid volvulus: a clinical study of 76 patients. Int J Colorectal Dis. 2004 Mar; 19: 134-142. doi: 10.1007/s00384-003-0534-8.

45. Grossmann EM, Longo WE, Stratton MD, Virgo KS, Johnson FE. Sigmoid volvulus in Department of Veterans Affairs Medical Centers. Dis Colon Rectum 2000 Mar; 43(3): 414-418.

46. Tsai MS, Lin MT, Chang KJ, Wang SM, Lee $\mathrm{PH}$. Optimal interval from decompression to semi-elective operation in sigmoid volvulus. Hepatogastroenterology 2006 May; 53(69): 354-6.

47. Safioleas M, Chatziconstantinou C, Felekouras E et al. Clinical considerations and therapeutic strategy for sigmoid volvulus in the elderly: A study of 33 cases. World J. Gastroenterol. 2007 Feb; 13(6): 921-4. doi: 10.3748/wjg.v13.i6.921.

48. Liang JT, Lai HS, Lee PH. Elective laparoscopically assisted sigmoidectomy for the sigmoid volvulus. Surg Endosc 2006 Nov; 20(11): 1772-1773. doi: 10.1007/ s00464-005-0665-9

49. Cartwright-Terry T, Phillips S, Greenslade GL, Dixon AR. Laparoscopy in themanagement of closed loop sigmoid volvulus. Colorectal Dis 2008;10(4): 370-372. doi: 10.1111/j.1463-1318.2007.01340.x.

50. Leung FW, Aljebreen AM, Brocchi E, Chang EB, Liao W-C, Mizukami T, et al. Sedation-risk-free colonoscopy for minimizing the burden of colorectal câncer screening. World J. Gastrointest. Endosc. 2010 Mar; 2(3): 81-9. doi: 10.4253/ wjge.v2.i3.81

51. Mizukami T, Yokoyama A, Imaeda H, Kumai K. Collapse submergence method: Simple colonoscopic technique combining water infusion with complete air removal from the rectosigmoid colon. Dig. Endosc. 2007; 19 : 43-7. doi: https://doi.org/10.1111/j.1443-1661.2007.00670.x.

52. Mizukami T, Hibi T. How I teach my trainees 'water navigation colonoscopy'. Am. J. Clin. Med. 2010; 7: 144-6.
53. Gatenby PA, Elton C. Endoscopic placement of flatus tube using "lasso" technique with snare wire. World J Gastroenterol. 2006 Sep 28;12(36):5902-3. doi: 10.3748/wjg.v12.i36.5902.

54. Cowlam S, Watson C, Elltringham M, Bain I, Barrett P, Green S, Yiannakou Y. Percutaneous endoscopic colostomy of the left side of the colon. Gastrointest Endosc. 2007 Jun; 65(7):1007-14. doi: 10.1016/j.gie.2007.01.012.

55. Jagetia A, Verma S, Mittal D, Agarwal P, Jain S, Prasad P. Sigmoidopexy (tube sigmoidostomy) as definitive surgical procedure for sigmoid volvulus. Indian $J$ Gastroenterol 1998 Oct-Dec; 17:129-30.

56. Lal SK, Morgenstern R, Vinjirayer EP, Matin A. Sigmoid volvulus an update. Gastrointest Endosc Clin N Am 2006 Jan; 16(1):175-87.

57. Davis B, Simson J. Percutaneous endoscopic colostomy in the management of incontinence and constipation in adults with neurological disease. Colorectal Dis $2003 ; 5: 110$

58. Gordon-Weeks AN, Lorenzi B, Lim J, Cristaldi M. Laparoscopic assisted endoscopic sigmoidopexy: a new surgical option for sigmoid volvulus. Dis Colon Rectum 2011; 54(5): 645-647. doi: 10.1007/DCR.0b013e31820b8071.

59. Raveenthiran V, Madiba TE, Atamanalp SS, De U. Volvulus of the sigmoid colon. Colorectal Dis. 12 (7 Online): E1-E17. doi: 10.1111/j.14631318.2010.02262.x

60. Bruusgaard C. Volvulus of the sigmoid colon and its treatment. Surgery. 1947; 22(3): 466-78.

61. Cereda JM, Chevrolet JC. Acute ventilatory failure secondary to a sigmoid volvulus. Thorax 1983 Nov; 38(11): 871-2. doi: 10.1136/thx.38.11.871.

62. Alam MK, Fahim F, Al-Akeely MH, Qazi SA, Al-Dossary NF. Surgical management of colonic volvulus during same hospital admission. Saudi Med J 2008 Oct; 29(10): 1438-42.

63. Atamanalp SS, Oren D, Aydinli B, Ozturk G, Polat KY, Basoglu M, et al. Elective treatment of detorsioned sigmoid volvulus. Turk J Med Sci 2008; 38(3): 227-34.

64. Clemente Ricote G1, Bañares Cañizares R, Sebastián Domingo JJ, Rábago Torre L, Menchén PL, Senent C, et al. Colonoscopic approach in the therapy of sigmoid volvulus. Rev Esp Enferm Dig 1990 Feb; 77(2): 129-32.

65. Das R, Hagger RW. Endoscopic fixation of rectal decompression tube for sigmoid volvulus. Ann R Coll Surg Engl 2008 Jul; 90(5): 425-6. doi: 10.1308/003588408X301244a.

\section{Como citar este artigo/How to cite this article:}

Ferreira LFP, Ferreira F Filho, Ferreira AFP, Lopes VV. A avaliação da atuação da colonoscopia no tratamento do volvo colônico . J Health Biol Sci. 2019 xxxxxx; 7(4):410-422.

J. Health Biol Sci. 2019; 7(4): 410-422 